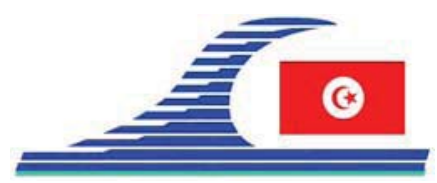

\title{
Tarbela dam: a numerical model for sediment management in the reservoir
}

\author{
Bilal Ahmed KHAWAJA ${ }^{1}$, Martin SANCHEZ ${ }^{1}$
}

1. Université de Nantes, LPG - UMR CNRS 6112, Nantes, France.

bilal.khawaja@univ-nantes.fr ; martin.sanchez@univ-nantes.fr

\begin{abstract}
:
Tarbela dam plays a vital role in Pakistan's economy as it is a major resource of irrigation water and electricity generation. Its reservoir has been rapidly filling since its start due to sediment transported and deposited by Indus River. In this study, a numerical model is realized taking in account different morphologic parameters and hydrodynamic processes to predict the evolution of sediment deposits due to river bed erosion and settling velocity in the reservoir.
\end{abstract}

\section{Keywords:}

Sediment transport - Numerical model - Reservoir sedimentation -Tarbela dam - River Indus - Pakistan

\section{Introduction}

Tarbela Dam (figure 1), the main resource of Pakistan in terms of electricity generation and irrigation supplies was impounded by the waters of Indus River in 1974 and within 25 years it has reached a state where major problems have occurred due to rapid deposit of sediment in the reservoir. The accumulation of deposited sediment thus forms a delta which has been travelling towards the main dam (10.6 km away in 2006) which endangers all the low level outlets including the power station which could be blocked by the liquefaction of the sediment under the severe earthquake.

The source of Indus River is situated in the Tibetan Plateau, at an elevation of $5500 \mathrm{~m}$ above sea level. Length of river upstream of Tarbela dam is $1127 \mathrm{~km}$ with an area of $169650 \mathrm{~km}^{2}$ out of which, $10 \%$ of the basin just above Tarbela is subjected to both; rainfall in winter and the heavy rainfall during the monsoon season from July to September. The remaining $90 \%$ of the basin lies between the Karakoram and Himalayas mountain ranges (WAPDA, 2005). Primary source of surface water is precipitation in the form of rainfall and snow and the glacier melt. Snowmelt contribution is greater than rainfall. Nevertheless, rainfall is directly linked with peak values. Mean annual

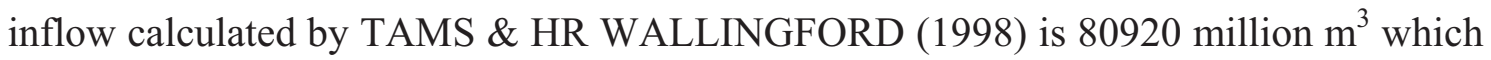
varies from year to year due to different temperature ranges and rainfall. The sediment load from the glaciers and the eroded sediment from the river banks thus travel with river and reach the reservoir. Here, the sediment deposits due to insufficient velocity DOI: $10.5150 / \mathrm{cmcm} .2009 .028-\mathrm{X}$ 
that generates favourable conditions for particle settling such that important storage capacity is lost. Sediment carried by Indus is deposited in the reservoir at an annual rate of about 200 million tons, corresponding to about $98 \%$ of the sediment inflow. The average composition of the deposits is $28 \%$ sand, $55 \%$ silt and $17 \%$ clay (TAMS \& HR WALLINGFORD, 1998). The predicted rate of sediment inflow was 0.294 billion $\mathrm{m}^{3}$ annually but the actual sediment inflow rate has been significantly lower with an average rate of 0.106 billion $\mathrm{m}^{3}$ which is $36 \%$ of the predicted rate (WCD, 2000). The minimum reservoir drawdown level was raised from initial $396 \mathrm{~m}$ to $417 \mathrm{~m}$ until 2006. Raising the minimum reservoir level will let sediment to deposit in upstream thus reduce the delta advancement. Consequently, it reduces the live storage and water availability in dry season. Length and area of reservoir are $97 \mathrm{~km}$ and $260 \mathrm{~km}^{2}$ respectively. Gross storage capacity is $14.3 \times 10^{9} \mathrm{~m}^{3}$ and original live storage capacity was $11.93 \times 10^{9} \mathrm{~m}^{3}$ which was reduced to $8.55 \times 10^{9} \mathrm{~m}^{3}$ until 2006. Average annual sediment deposit is $0.134 \times 10^{9} \mathrm{~m}^{3}$ and sediment volume up to 2006 was $4.23 \times 10^{9} \mathrm{~m}^{3}$.

\section{Methods}

Methods to lessen the problem of sedimentation are usually based on reduction of the inflow of sediment, the manipulation and control of the reservoir processes and the mechanical removal of deposits. Experimental work of SERAJI (1992) related to flushing of the sediment was thoroughly studied. A numerical model is being realized taking in account different transversal sections of the reservoir up to $100 \mathrm{~km}$, annual hydrological cycle, monthly reservoir storage levels, rate of erosion, rate of deposition, granulometric distributions and settling velocity to define and explain the morphological changes and deposition of the sediment in the reservoir over different time periods. RESSASS, another 1-D model made by (TAMS \& HR WALLINGFORD, 1998 ) is different from this model as we used the Krone model to calculate the concentration at the downstream of each section which gives more accurate results. A number $\mathrm{N}=37$ of sections of the reservoir all along the length of $96 \mathrm{~km}$ have been taken into account. Figure 2 shows the schematic discretization of the transversal sections of the reservoir. Average widths of each section were known from the bed of the river $\eta_{o}$, at the interval of $5 \mathrm{~m}$ vertically till $472 \mathrm{~m}, \eta_{\max }$, which is the maximum operating level of the reservoir. The values estimated by interpolation of the local width $L_{i}$ were then used to calculate the horizontal surface area $S_{i}$ of each section as a function of the level $\eta$. The reason of these calculations is to get the local flow $Q_{i}$ of water in each particular section at any interval of time. The flow $Q_{i}$ depends on the level $\eta, Q_{\text {output }}$ and $Q_{\text {input }}$, which are respectively the reservoir output and input water flow. We used $\eta$ as the average level of the reservoir each month to calculate the total horizontal surface area $S_{T}$. The input water flow $Q_{\text {input }}$, is given by natural river flow. Average values of river flow vary from $420 \mathrm{~m}^{3} \mathrm{~s}^{-1}$ in winter to $6220 \mathrm{~m}^{3} \mathrm{~s}^{-1}$ in summer due to monsoon rains and 
Himalaya and Karakoram glaciers melt. Output water $Q_{\text {outut }}$, also varies each month due to the water usage for electricity generation and water evacuation for irrigation supplies.

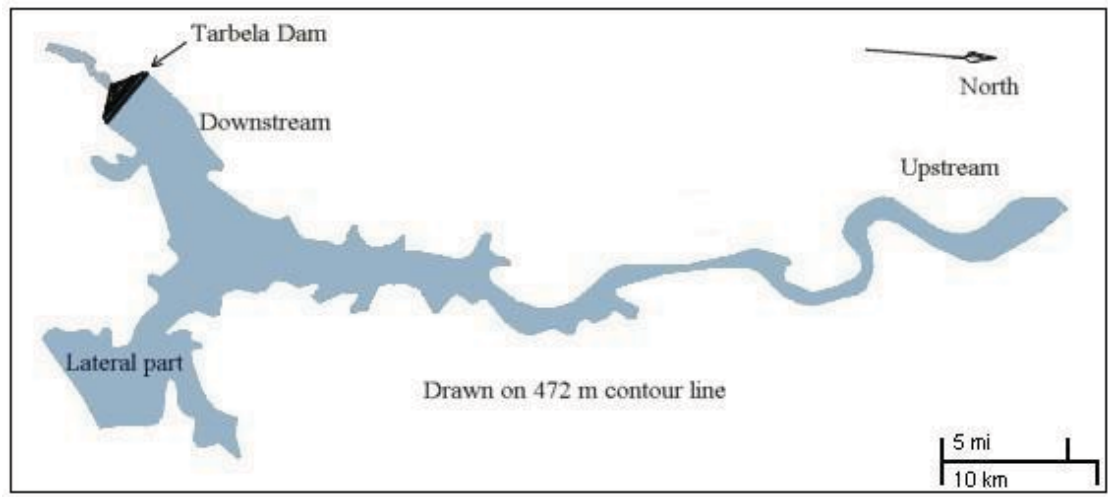

Figure 1. Tarbela Dam and reservoir (schematic diagram).

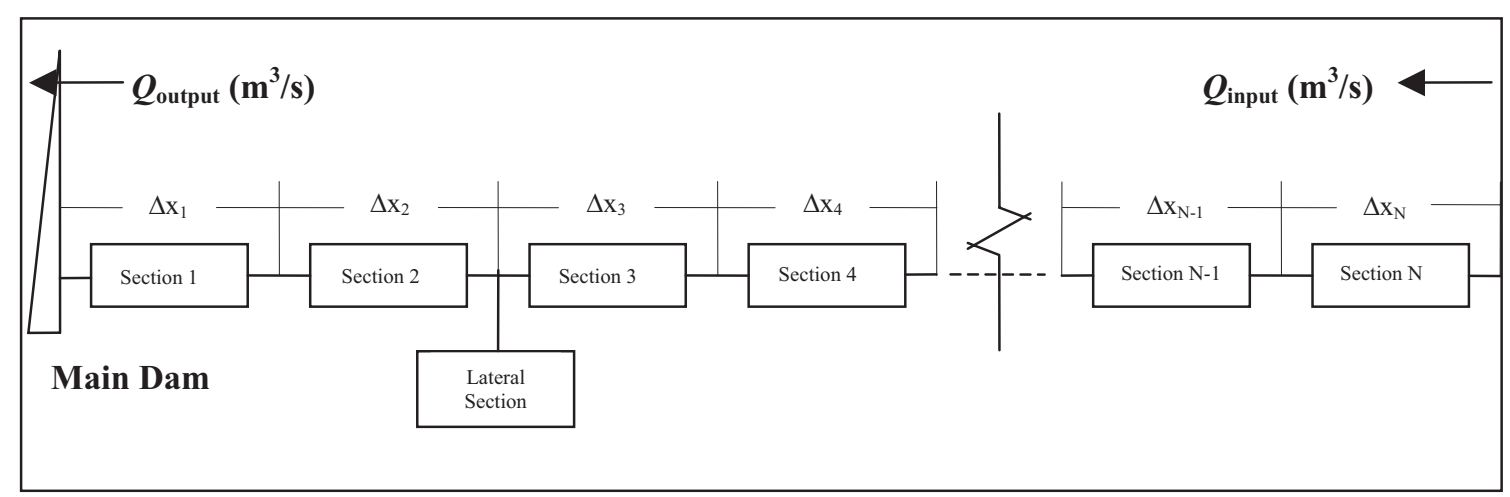

Figure 2. Schematic discretization of the transversal sections of the reservoir.

Some of the equations that govern in this whole model are:

$$
\begin{gathered}
Q_{i}=Q_{\text {input }}+\frac{1}{S_{T}(\eta)} \sum_{j=i}^{N} S_{j}(\eta)\left(Q_{\text {output }}-Q_{\text {input }}\right) \\
S_{T}(\eta)=S_{L}+\sum_{i=1}^{N} S_{i}(\eta)=S_{L}+\sum_{i=1}^{N}\left(L_{i}(\eta) \times \Delta x_{i}\right)
\end{gathered}
$$

where: $S_{L}$ is lateral surface area of the river, which is calculated in terms of $\eta$. Krone model is used to calculate the concentration at the downstream of each section resulting from deposition. The reduction of the concentration $\Delta \bar{C}_{i}$ in a section between upstream and downstream is given by:

$$
\Delta \bar{C}_{i}=-\frac{W_{o} C_{o}}{d}\left(\frac{\tau_{c}-\tau}{\tau_{c}}\right) \Delta t_{i}
$$

where: $C_{o}$ is concentration near river bed, $W_{o}$ is the settling velocity near the river bed, which is calculated as a function of $C_{o}$ through an Owen power law, $\tau$ is the shear stress, which is calculated as function of the square of local velocity, $\tau_{c}$ is critical shear stress above which the sediment do not deposit and $d$ is mean depth. 
The main equation to calculate the reduction by deposition of the transversal section is:

$$
\Delta S_{i}{ }^{++\Delta t}=\Delta S_{i}{ }^{t}-\frac{1}{(1-n) \rho} Q_{i} \frac{\Delta \bar{C}_{i}}{\Delta x_{i}} \Delta t_{i}
$$

where: $n$ is the porosity, $t$ is time and $\Delta t_{\mathrm{i}}$ is the time step.

Erosion is considered as a function of $Q_{\text {input }}$, but only in the downstream region when reservoir level is low enough that a fluvial regime is observed.

\section{Results}

Figure 3 shows the evolution of sediment deposition according to the actual data received from Tarbela authorities calculated by the field surveys. Original river bed level and the initial survey data of the year 1979 has been kept constant in the model and in the following figures as well and four different years are being selected to compare the evolution of sediment deposition from the observed data and calculated by the model. We did sensibility study and changed the parameters of law describing the settling velocity $W$, the critical shear stress for deposition $\tau_{c}$, to obtain the best results. Subsequently, to carry out the sensibility study, we kept changing the values of one parameter keeping others constant as initial values. Final result is presented in figure 4.

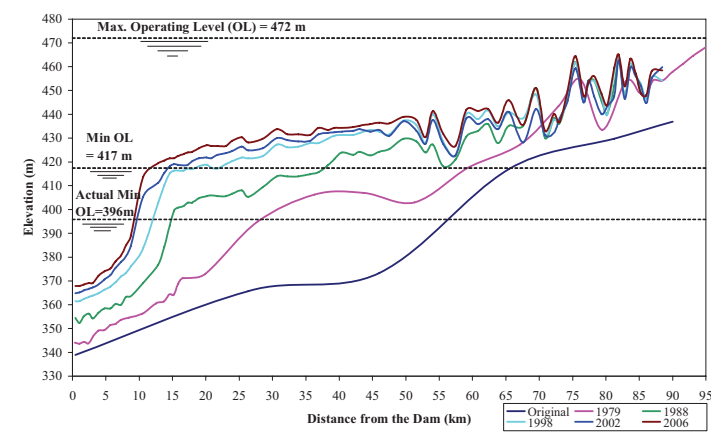

Figure 3. Observed annual longitudinal profiles of deposits in the reservoir.

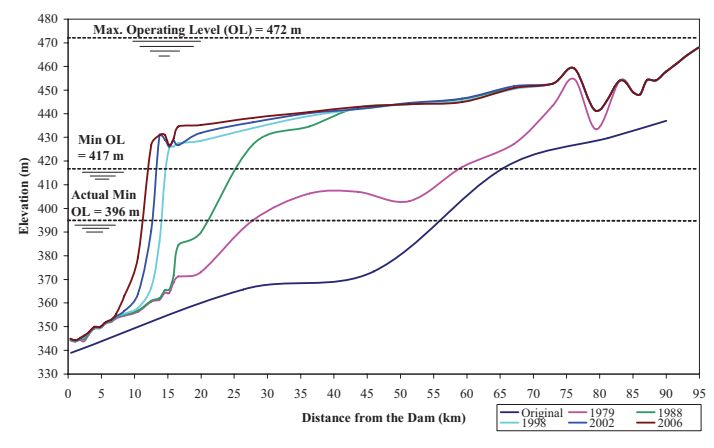

Figure 4. Annual profiles obtained from the model.

\section{References}

SERAJI M.H.S. (1992). Etude du transport sédimentaire associé au phénomène de chasse d'un barrage. Thèse de Doctorant, Université de Caen, $162 \mathrm{p}$

TAMS CONSULTANTS INC., HR WALLINGFORD LTD. (1998). Tarbela dam sediment management study - final report. Commissioned by WAPDA, Lahore.

WAPDA -Pakistan's Water and Power Development Authority- (2005). Tarbela Dam Project, Reservoir Sedimentation Report. Lahore, 40 p.

WCD -World Commission on Dams- (2000). Tarbela dam and related aspects of Indus River basin of Pakistan-final report. Asianics Agro-Dev. Int (Pvt) Ltd, Islamabad, $181 \mathrm{p}$. 